\title{
О СЕМАНТИЧЕСКОМ ПОТЕНЦИАЛЕ ПОРЯДКОВЫХ ЧИСЛИТЕЛЬНЫХ В РУССКОМ ЯЗЫКЕ
}

\author{
С. М. Белякова \\ Тюменский государственный университет \\ ON THE SEMANTIC POTENTIAL \\ OF ORDINAL NUMERALS IN THE RUSSIAN LANGUAGE
}

\author{
S. M. Belyakova \\ Tyumen State University
}

\begin{abstract}
Аннотация: статья посвящена проблеме сущности и особенностей семантического развития порядковых числительных первого десятка, функиионируюших в национальном русском языке. Делается вывод об активной вовлеченности данной лексико-грамматической группы в прочесс функциональной транспозиции (В. Г. Гак). Развитие семантики порядковых числительных происходит по регулярным моделям, соотносимым с набором значений. Лексемы первого десятка делятся на две группы, отражающие особенности восприятия порядковых номеров объектов. Наиболее разветвленной системой вторичных значений обладает числительное первый, что объясняется сакральностью и семантической нагруженностью феномена начала. В развитии качественных значений порядковых числительных прослеживается единая общерусская традииия.
\end{abstract}

Ключевые слова: порядковые числительные, качественная семантика, модели развития значений, русский язык, функцииональная транспозиция.

\begin{abstract}
: the article is devoted to the problem of the essence and features of semantic development of ordinal numerals of the first ten functioning in the national Russian language. The conclusion is made about the active involvement of this lexical-grammatical group in the process of functional transposition $(V . G$. Gak). The development of the semantics of ordinal numerals is based on regular models that are correlated with a set of values. The top ten lexemes are divided into two groups that reflect the perception of ordinal numbers of objects. The most extensive system of secondary values has the numeral first, which is explained by the sacredness and semantic loading of the phenomenon of the beginning. In the development of qualitative values of ordinal numerals, a single all-Russian tradition can be traced.
\end{abstract}

Key words: ordinal numbers, qualitative semantics, models of value development, Russian language, functional transposition.

...Потому что все оттенки смысла умное число передает.

\section{Введение}

Число является уникальным феноменом, значимым как в общечеловеческом контексте, так и в каждой отдельной культуре. Перед нами не только математическая сущность, но и своеобразный конгломерат культурных, сакральных и бытовых представлений. Это объясняется, в первую очередь, тем, что числа «обладают особой абстрактно-конкретной, идеально-материальной природой» [1, с. 313]. Несмотря на кажущуюся простоту языковых обозначений чисел, в них проявляется многослойность: сохраняются очень древние представления, на которые зачастую накладываются современные ассоциации. При этом отчетливо видна специфика количественных и

(C) Белякова С. М., 2020 
порядковых числительных, проявляющаяся не только в грамматических особенностях, но и в семантике.

В данной статье рассматривается тот потенциал порядковых числительных (в пределах первого десятка), который реализуется в семантическом варьировании, приводящем к фразообразованию. Предлагается гипотеза, в соответствии с которой порядковые числительные русского языка активно вовлечены в процесс функциональной транспозиции (В. Г. Гак) и близки к именам прилагательным.

Материалами, позволяющими максимально полно выявить их семантический потенциал, на наш взгляд, должны быть данные не только литературного языка, но и народных говоров, взаимодополняющие и оттеняющие друг друга. Источниками фактического материала стали: Словарь русского языка (MAC) [2], диалектные лексиконы [3; 4] и др., фразеологические словари, а также Национальный корпус русского языка (основной подкорпус) [5].

Основным лингвистическим методом нашего исследования является описательный метод, включающий в себя конкретные методики (структурные и интерпретационные). Среди структурных методик наиболее значимыми выступают дистрибуционный анализ и элементы компонентного анализа, применяемые для выявления контекстуальной семантики числительных. Сопоставительный метод используется в целях сравнения нормативных и узуальных языковых фактов, а также материалов русского литературного языка и субстандартной диалектной речи. В работе реализованы некоторые элементы культурологического подхода к изучению диалектных явлений.

В соответствии с грамматиками русского языка порядковые лексемы, отнесенные к классу числительных, квалифицируются как слова, которые указывают на место в счетном ряду, они выступают показателями порядкового номера некоторого объекта в исчислимом множестве [6]. Но многие исследователи отмечают и их неоднозначность, например: «...исторически и в результате соотношения как с собственно числительными, так и с прилагательными, семантическое наполнение этих слов стало амбивалентным. Наряду с основным значением (называния порядка предметов при счете), они приобрели новую семантику, связанную с называнием качеств и свойств предметов, а также нередко с оценочными коннотациями» [7, с. 445]. Следует сказать, что место порядковых числительных в языке определяется лингвистами по-разному, в частности, многие специалисты в области романских языков относят их к классу прилагательных (см., например, [8; 9]). Близкую трактовку этого вопроса находим в трудах В. Г. Гака, который писал: «Количественные и порядковые числительные объединяются общим значением числа. Но их грамматические признаки различны. Порядко- вые ничем, кроме значения, не отличаются от прилагательных, они совмещаются с детерминативами (...). Поэтому их нужно считать прилагательными, внутри которых они могут трактоваться как особый семантический разряд» [10, с. 129]. Однако и контекстуальные значения таких числительных могут быть весьма специфичны. Таким образом, можно сказать, что в целом языковой статус порядковых числительных в русском языке до конца не определен и является предметом научной дискуссии. Привлечение широкого материала, в том числе и фактов некодифицированной речи, будет способствовать решению этой проблемы.

\section{Анализ семантического варьирования порядковых числительных. Результаты исследования}

Прежде всего следует отметить, что буквально каждое из порядковых числительных специфично как по сравнению со своими «собратьями», так и в сопоставлении с соответствующими количественными обозначениями.

Интересно, что с мнением лингвистов совпадает и мнение математиков, например, А. А. Френкеля и И. Бар-Хиллела, которые констатируют, что числа отличаются друг от друга «характерными индивидуальными свойствами - подобно тому, как различаются между собой люди» (Цит. по: [11]).

Самым «богатым», обладающим максимально широким диапазоном семантического варьирования, является числительное первый. Это объясняется, прежде всего, присущей ему семантикой начала, являющейся исключительно «сильной», значимой в любом языке. И хотя, как отмечает Н. Б. Мечковская, в объективном мире начала не существует, она же пишет, что «в сознании человека достаточно рано... возникла необходимость в концептах “начало” и “конец" - в качестве пары пространственно-временных координат бытия, допускающих количественную оценку» [12, с. 109]. Важно и то, что в сравнении с количественным числительным один, значение которого, по мнению лингвистов (см., например, [13; 14]), осознается не в изолированном употреблении, а лишь при сопоставлении с последующим рядом чисел, лексема первый сразу содержит указанную семантику.

Приведем вначале некоторые количественные данные, ярко (хотя далеко не исчерпывающе) характеризующие объем семантики порядковых числительных первого десятка. С опорой на данные МАС укажем, что для лексемы первый отмечается 6 значений и 10 оттенков значения (обозначим их как 6/10), для слова второй это соотношение $3 / 2$, для числительного третий - 3/0. (Во внимание принимаются лишь числительные, а не их субстантивированные формы, такие как, например, первое, второе, третье 
в качестве названий блюд, подаваемых во время обеда.) Все остальные числительные имеют лишь по одному, прямому, значению. Однако словарные статьи некоторых из них сопровождаются примерами - фразеологическими сочетаниями, что, разумеется, свидетельствует о более широком потенциале их семантического варьирования, что и будет показано далее. Богатый материал дают также фразеологические и диалектные словари.

Лексема первыц̆ заслуживает отдельного описания. При помощи обобщения значений, приведенных в словаре, можно выделить несколько семантических классов (таксонов), с которыми соотносится данное числительное.

Прежде всего это время, поскольку обозначение порядка счета связано не только с предметами, но и (чаще всего) - с событиями, а их последовательность и осознается как движение времени. Здесь маркируется главным образом начало такой последовательности: первые шаги, на первых порах, первый блин комом, диал. первые года (тюм.), диал. первая вода «весеннее половодья» (яросл.), диал. в первую голову «сначала» (Даль, без указания места). Заметим, что данное числительное отражает как линейную модель времени, когда за названным событием следуют другие, однотипные, «нанизывающиеся» на ось времени (первый полет в космос, Первый Спас), так и циклическую (первый снег, первая гроза).

Традиционное мировоззрение, как правило, сакрализует начало какого-либо процесса, что ярко отражено в многообразных диалектных номинациях. Среди них, в частности, обозначение символического начала сельскохозяйственных работ: первый укос, первая коса (тюм.), первый сноп (брян.), первая соха (калин.). Сакральный смысл, ритуальность сопутствуют инициальности и других событий, имеющих обрядовое значение. Так, первое вино - это обозначение сватанья в свадебном обряде (пск.); первый стол угощение у жениха сразу после венчания (калуж.); первое воскресенье угощение в доме тещи в первое воскресенье после свадьбы (урал.); первая встреча / первыц встречник - в похоронном обряде: кусок холста, подаваемый первому встречному, когда несут покойника (влад.). Ср. также сочетание перву постель сберечь - «сохранить девственность до замужества» (томск.). Приведем некоторые контексты: Первый сноп несут в изерковь, когда сеют озимую рожь, его зерном первым засевают (брян.). // Первое вино сватаются, второе вино - смолвины (пск.). // А потом было первое воскресенье, все шли ктёщее. Как видим, особенно важна инициальность для свадебного и похоронно-поминального обрядов.

Для жителей села также релевантно подобное обозначение домашних животных, впервые включаемых в трудовые процессы: первая соха «о жеребен- ке, которого впервые запрягли для пахоты» (твер.), первыл стадом / по первому стаду «о впервые отелившейся корове, выгнанной в стадо» (ряз.).

Другой оттенок общего значения, связанного со временем, - фиксация его небольшого отрезка, то, что можно кратко обозначить как «сразу же». Сюда относятся номинации с первого взгляда, с первого слова, с первого знакомства, диал. с первой руки (урал.).

Примечателен также тот факт, что в календаре, используемом в нашей стране, имеется пять праздников разного ранга, приходящихся на первое число месяца (январь, апрель, май, июнь, сентябрь). При этом для трех из них речевой узус предписывает наименование с числительным (Первое апреля, Первое мая, Первое сентября), а не их официальное название. Разумеется, установление именно таких дат для праздничных и памятных дней имеет разные причины, в том числе исторические, однако представляется, что в некоторых случаях, например, при выборе даты для Дня защиты детей, временная инициальность и имплицитная сакральность могли сыграть свою роль. Здесь можно говорить о тройной инициальности: это не только начало месяца и сезона, но и символическое начало школьных каникул.

Следующая категория, с которой соотносится числительное первыци, - пространство. Несмотря на логическую очевидность такой ассоциации (первый - тот, который ближе всего к наблюдателю), подобные примеры единичны: первый план, диал. первая линия «передовая линия боя» (арх.).

Восприятие временной и пространственной близости объектов приводит к развитию семантики «непосредственно»: из первых рук / уст.

Инициальность, особая маркированность начала порождает семантику суперлятива, обозначения лучшего, превосходящего других: звезда первой величиHbl, первый среди равных, первое дело, диал. первой девкой ходить (тюм.), диал. первая рука «первый сорт» (пск.), диал. первая коса «лучшее сено, скошенное в начале сенокоса» (тюм.), диал. первого лица «хорошая невеста» (перм.). См. контексты: Первая рука - это хорошая рожь, вторая рука похуже, $c$ костром (пск.). // Плаття родительскы на детей перешьвали. Имне бапка своё платьте перешьвала. Дак я ищё первой дефкой ходила (тюм.). // Перва коса - сено хоро́шо (тюм.). Лучшее по качеству может восприниматься как главное: играть первую скрипку, диал. первый угол «красный угол, место в избе, где находятся иконы», см. контекст: Это главный угол, первый угол называется, коло него икона, стоит стол (новосиб.). Путем сочетания числительного первыц с частицей НЕ передается семантика отрицательной оценки, низкого качества: не первой молодости / свежести. 
Лексема первыц может выступать своего рода экспрессоидом, передавая широкое значение интенсивности процесса: всыпать по первое число, диал. за первую душу «с удовольствием, охотно» (томск.), первый жар «о начале драки» (свердл.). См. в контексте: Раньше масленики не брали, а теперь за перву душу съедят (томск.).

Анализ остальных обозначений позволяет выделить ряд моделей расширения семантики, присущих данному лексико-грамматическому разряду слов русского языка. Эти модели соотносятся с определенным набором числительных, хотя в ряде случаев происходит их наложение.

Обратимся к числительному второй. Во многих случаях его семантика ориентируется на лексему nервый, на выстраивание некой параллели с ней. Так, важным является выражение подобия, замещения первого (известного объекта или лица): второй Рим; вторая древнейшая профессия; второй Чадаев, мой Евгений... (А. Пушкин), что представляет собой разновидность перифраза.

Однако данное числительное в меньшей степени соотносится с категорией времени, хотя отмечаются и такие употребления, например, второе пришествие как ироническое обозначение отдаленного будущего, неопределенно далекого срока. Но чаще оно приобретает качественные значения. Среди них номинации более низкого (или просто низкого) качества объекта, что чаще всего выражается при помощи сложных прилагательных, где одной из основ и выступает втор- (второсортный, второразрядныий). Реализацию этого значения мы обнаруживаем в знаменитом булгаковском выражении осетрина второй свежести. Любопытный парафраз, составленный из двух известных цитат, обнаружен нами в материалах НКРЯ (Форум «Наши дети», 2004): ...нуи и гадость эта ваша заливная рыба - осетрина второй свежести. Сюда же можем отнести диал. второе дело - дело не из важных, неспешное (олон.). Значение «нечто неглавное» воплощено в сочетаниях играть вторую скрипку, быть на вторых ролях, отойти на второй план. (Интересно, что при создании этих метафор сферой-донором выступает искусство.) В последнем случае семантика раскрывается через пространственную метафору. Ординарность, неоригинальность второго может быть проиллюстрирована выражением каждый второй, т. е. любой, всякий: каждый второй может подтвердить мои слова.

Ориентацию на понятие «первый» содержат и параллельные выражения, связанные с обозначением передачи чего-либо (чаще всего информации) непосредственно или через посредников: из первых рук / уст - из вторых (третьих) рук / уст.

В плане аксиологичности второй может нести положительную оценку («такой же хороший, как первый») или отрицательную («не такой хороший, как первый»). Иллюстрацией последнего служит, например, детская присказка Первое слово дороже второго. Положительную оценку имеют фразеологизмы вторая молодость, второе дыхание, где рассматриваемое числительное используется для обозначения возвращения жизненных сил, энергии, бодрости.

Что касается диалектного материала, то здесь мы не находим яркого проявления особой семантики, значимости феномена второго для народного мировоззрения. Отметим как оригинальные лишь выражения второй слой - «о детях от второго брака» (тюм.), что представляет собой растительную метафору, и вторая рука «самый близкий помощник, правая рука» (дон.) - соматическая метафора.

Переходя к характеристике следующего числительного, отметим, что лексемы первыц̆, второй, третий составляют компактную группу, важной функцией которой является ранжирование по качеству предметов или процессов. Это обозначение сортов продуктов, а также мест, занимаемых спортсменами на соревнованиях. Разумеется, спортсмен может занять какое угодно место среди всех участников, однако социально значимыми и специально награждаемыми считаются только первые три. Близко к этой семантике и обозначение скоростей, но здесь ранжирование имеет обратный порядок: высшей называется третья из них. Примерно такая же картина со звонками в театре: наиболее важным считается третий звонок, после которого вход в зал закрывается и начинается представление. Подобные примеры Д. В. Сичинава называет «иерархической метафорой» [6].

Данная лексема имеет и еще одну важную особенность функционирования: два первых объекта, на которые ориентирован третий, зачастую специально не номинируются при помощи числительных, они являются таковыми «по умолчанию». Так, в общерусском употреблении существует сочетание третьего дня «позавчера», но с ним не соотносятся обозначения двух других дней, предшествующих этому третьему. (Сочетание второго дня в значении «вчера» отмечено в НКРЯ, но не фиксируется словарями.) Аналогично в говорах функционируют выражения в третьем годе / третьего году, третьей зимой и т. п. Отметим также третий возраст «пожилой возраст» (своеобразный эвфемизм) и третье поколение «внуки» - без указания на первое и второе.

Значение «рядовой, ординарный», присущее числительному второй, получает дальнейшее развитие, усиливается, приобретая семантику «посторонний, лишний» в выражениях третье лицуо и третий лишний. Кроме того, следует отметить и изначальную, исходную бинарность (контрастность) восприятия 
лиц и явлений: третий - «лично не заинтересованный в чем-либо, касающемся двух сторон, лиц», ср. также третейский (суд, судья), третий мир (страны третьего мира).

Диалектный материал дает нам образные номинации домашних животных в соответствии с их возрастом: на третью соломку пошла (о корове) (калин.), на третью траву пошёл (о теленке или жеребенке) (твер.), по третьей траве (якут.), третий хомут (яросл.).

В говорах в парадигме «один - три» номинируется также и родство людей: первое колено «самые близкие родственники»-второе колено «двоюродные братья и сестры» - третье колено «дальние родственники» (волог., новосиб.). Ср. также: первые братаны «двоюродные братья и сестры»-вторые братаны «троюродные братья и сестры» (перм.).

Сакральная символика числа три проявляет себя и в порядковом числительном, особенно это характерно для традиционной народной культуры. Известно, что в фольклорных текстах совершение какого-либо действия в третий раз имеет особое значение наивысшей степени или завершенности цикла. Как пишет С. М. Толстая, число 3 «символизирует завершенность и полноту некоторой последовательности, имеющей начало, середину и конец, и чаще всего фигурирует в предписаниях трижды совершать то или иное магическое действие» [15, с. 489].

Подтверждение этому находим в диалектном материале. Так, сочетание третий зной сопровождается в словаре (СРНГ) развернутым описанием «третья очередь мыться в бане (обычно поздно вечером, представляющая по народному поверью опасность для человека)»: Романчик в сумерки ходил в байну, чертей боялся, в третий зной нельзя в байну третьему человеку (новг.). Аналогичную культурно обусловленную семантику имеет и выражение третий пар: В баню в 12 часов (ночью в этот час, говорят, третий пар бывает) нельзя идти, худо будет (иркут.). В эту парадигму вписываются и сочетания с темпоральным значением первые / вторые / третьи петухи (до третьих петухов), где последнее означает разгул перед рассветом нечистой силы, исчезающей с третьим пением петухов. Таким образом, данное числительное соотносится с символикой опасности и запрета.

Сакральность третьего отражена и в христианской похоронно-поминальной обрядности, см., например: Куда наведьвается его душа на третий, девятый, сороковой? (А. Битов, 1981).

Числительное четвертый, пожалуй, наименее представлено в имеющемся материале. Однако можно отметить, что здесь продолжает развитие вступающая в силу в предыдущем случае модель филиации семантики, которую можно обозначить как «плюс один». Речь идет о существовании в природе (это может быть строение тела человека или животного, физические особенности мира и т. п.) или в обществе строго определенного количества элементов. Поэтому «появление», чаще всего в качестве метафорического обозначения, еще одного элемента маркируется при помощи сочетания с соответствующим порядковым числительным, например: третий глаз, третий полюс земли (Эверест), четвертая власть, четвертое измерение. Так, МАС дает следующее толкование последнему из них: «О чем-л. недоступном для чувств, недоказуемом, мистическом» [7. Т. 1, с. 647]. Четвертым измерением называют также время. Аналогичная модель представлена и другими числительными: пятый элемент, пятый океан, пятылй угол, пятое время года, шестое чувство, седьмой континент, восьмое чудо света. С некоторым допущением сюда можно отнести и выражение пятая колонна - от названия пьесы Э. Хемингуэя о гражданской войне в Испании, где враги наступали на город четырьмя колоннами (ассоциация с четырьмя сторонами света), а пятая колонна, т. е. предатели, находилась внутри. Метафоричность подобных выражений можно охарактеризовать словами Г. Гессе: «Все было на одно измеренье богаче, на одно значение глубже, было игрой и символом».

Системы обозначений первыц - третий или первый - четвертый демонстрируют определенную целостность, ориентацию на первый элемент. На рубеже четвертого этот импульс затухает, но появляются новые качества. Такая закономерность коррелирует с историческим и структурным выделением в русском языке двух групп числительных в пределах первого десятка. По мнению исследователей, в частности, Ю. Иноуэ, «...система счетных имен древних индоевропейских языков имела двойную структуру, т. е. внутри десятичной заключена четверичная. И если десятичная система являлась системой для счета, то в четверичной системе отображается визуальная способность человека воспринимать числа» [16, c. 60].

Вторую группу числительных (пятый-десятый) целесообразно рассматривать как некое единство, с отчетливо видимыми общими закономерностями и моделями, хотя при этом нельзя отрицать и определенную специфику некоторых лексем. В общем плане пока можем отметить такие явления, как больший семантический и сакральный потенциал нечетных числительных и значительную фразеологическую синонимию.

Так, числительное пятый (а также седьмой, девятый и десятылй) развивает семантику в основном в соответствии с моделями «множество», а также «интенсивность», требующей экспрессивности их выражения. Конкретная реализация первой из них 
происходит, главным образом, в двух направлениях: а) «далекий», б) «ненужный».

Значение «далекий» может иметь пространственное значение, см., например, диал. на седьмой порядок (идти, ходить и т. п.) «далеко от дома» (горьк.). Однако чаще так обозначается далекая родня (что особенно актуально для говоров), когда кровные связи метафоризируются как пространственная близость / отдаленность: от пятой курицы десятый ијыплёнок (тобол.), седьмая (десятая) вода на киселе, седьмая кожа не вороть (невывороченная) (урал.), девятый зуб (урал.), девятой курицы десятое яичко (иркут.).

Значение «ненужный» (часто речь идет о человеке) реализуют фразеологизмы пятое колесо в телеге, нужна как собаке (кобыле) пятая нога, пятая спица в колеснице, диал. девятый мосол (кемер.), дело десятое. См., например: Двушка на «Аэропорте» мне нужна как собаке пятая нога (А. Волос, 2001). Множественность здесь связана с избыточностью или чем-то не существующим в природе, а потому лишним.

Интенсивность чаще всего передают лексемы седьмой и девятый: до седьмого пота «до крайнего утомления, до полного изнеможения (работать, трудиться и т. п.)», попадать (попасть) на седьмое небо, «испытывать чувство восторга, блаженства, безграничного счастья и т. п.», на седьмом небе «безгранично счастливым, глубоко удовлетворенным (быть, чувствовать себя)», девятый вал «наиболее бурное, сильное проявление чего-либо грозного, наивысший подъем, взлет чего-либо», диал. девятая волна «самая большая, сильная волна» (арх.), диал. девятый забай «о человеке, который любит много говорить (свердл.).

Пародийное использование числительного седьмой (порядковый номер при фамилии, который мыслится его носителем как нечто значительное) находим в рассказе А. П. Чехова «Жалобная книга»: За начальника станции Иванов 7-й. - Хоть ты и 7-й, а дурак.

Укажем на частое объединение в составе бинома числительных пятый и десятый, что может объясняться влиянием рифмы, усиливающей экспрессию: с пятого на десятое, пятое-десятое, диал. на девяmу-на десяту (томск.) и т. п. со значением непоследовательности, небрежности, неточности. Например: ...не говорите потом, что у вас какая-то там пятая или десятая колонна виновата... (Новые известия, 24.03.2020).

В рассматриваемой группе числительных сравнительно немного примеров, позволяющих противопоставить материал литературного языка и диалектов, скорее они дополняют друг друга, находясь в русле общей традиции. Однако несколько подобных случаев есть. В литературном употреблении это, в частности, сочетание пятый пункт (вопрос) - указание на национальность в анкетах советского периода: Он не знал, что будет вскоре значить для сотен тыссяч людей ответить на пятый вопрос анкеть... (В. Гроссман, 1960), а также очень популярная пятая колонна как обозначение предателей национальных интересов. Они имеют книжное происхождение, и параллелей к ним в говорах не обнаруживается.

В диалектном же дискурсе весьма частотны сочетания девятая пятница (праздник в честь памяти святой мученицы Параскевы, приходящийся на девятую пятницу после Пасхи) и девятылй день как обозначение одного из поминальных сроков. Например: Девята пятьница, от Паски ли чё ли девята пятницза (тюм.); После похорон девятый день, потом сороковой день (тюм.). Таким образом, за этим числительным закреплена сакральная семантика христианского происхождения. Впрочем, народно-христианский дискурс дает много примеров и других обозначений с применением порядковых числительных, что может стать предметом отдельного рассмотрения.

Что же касается числительного десятый, то нами не зафиксирована у него семантика завершения, нет также и противопоставления первому, как можно было бы предположить. Укажем в связи с этим на мнение этнолингвистов М. М. Валенцовой и И. А. Седаковой, что «противопоставление первого последнему не всегда актуально, эти признаки могут выступать как самостоятельные, непарные, семантически не соотносимые друг с другом» [17, с. 674]. Судя по имеющемуся материалу (извлеченному главным образом из НКРЯ), эта лексема либо развивает значение «неглавный, неважный» (дело десятое, вопрос десяmыıй), либо имеет семантику повтора, совершения какого-либо действия много раз, что, безусловно, имеет компонент экспрессивности (и такие контексты очень частотны). Например: В десятый раз просить: «Не уезжай»? (С. Довлатов, 1983); ...настроился посмотреть их в десятый раз (Ю. Трифонов, 1976) и т. п. Таким образом, здесь преобладает модель «множество».

В данной группе развита фразеологическая синонимия, что свидетельствует о значительной экспрессивной составляющей рассматриваемых порядковых числительных. См., например: видеть седьмой (десятый) сон «крепко спать», седьмая (десятая) вода на киселе и т. п. Имплицитная метафоричность присуща и другим лексемам, это позволяет трансформировать фразеологизмы, «играть словами»: Друг-гвинеец так и прёт - Всё больше отставание, - Ну, я надеюсь, что придёт Второе мне дыхание. Третее за ним ишу, Четвёртое дыханье, - Ну, а на пятом сокрашу С гвинейцем расстоянье! (В. Высоцкий).

\section{Заключение}

Итак, подводя итоги проведенному исследованию, можно сделать следующее обобщение. Анализ материала подтвердил нашу гипотезу о вовлеченно- 
сти русских порядковых числительных в тот процесс, который В. Г. Гак назвал «функциональной транспозицией», т. е. приспособлением слова для выполнения функции иной части речи [10]. В ряде случаев (и достаточно регулярно) они играют роль имен прилагательных с их качественной семантикой, аксиологической и экспрессивной нагруженностью.

Регулярность подтверждается тем фактом, что развитие качественной семантики порядковых числительных русского языка проходит по определенным моделям, соотносимым с набором соответствующих лексем. Наиболее отчетливо выделяются следующие модели:

- «подобие» (второй, третий);

- «плюс один» (третий - восьмой);

- «множество» (пятый - десятый);

- «интенсивность» (седьмой, девятый).

Модели коррелируют с целым рядом значений: время (разные оттенки темпоральности, в том числе срок), пространство (далекий), родство, возраст, лучший / нелучший (рядовой), главный / неглавный, непосредственный / опосредованный, опасный, ненужный.

Русские порядковые числительные первого десятка в соответствии с развиваемой семантикой и функционированием разделяются на две группы: первыци - четвертылй и пятый - десятый. При этом наши выводы, касающиеся употребления этой особой лексической группы русского языка, дополняют выводы Ю. Иноуэ о специфике количественных числительных. Он пишет: «Различие в восприятии количества между 4 и 5 связано с визуальной способностью человека воспринимать предметы. Это объясняется отдельными процессами восприятия, т. е. «мгновенного восприятия» до 4 предметов и «считанья одного за другим» от 5 [17, с. 62]. В результате анализа семантики и употребления порядковых числительных, как нам представляется, были получены убедительные данные, свидетельствующие о том, что в диапазоне первый - четвертый происходит преимущественно определение порядка предметов или явлений, ориентированное на начало счета, а начиная с пятого - их недискретное восприятие как множества или средства экспрессивации. Возможно, в этом и заключается существенная разница между количественными и порядковыми числительными.

Наиболее разветвленной системой вторичных значений обладает числительное первыц̆, что объясняется сакральностью и семантической нагруженностью феномена начала. Среди других лексем более активны обозначения нечетных чисел (без отчетливо выраженной аксиологичности). Ср. в связи с этим заключение С. М. Толстой о преимущественно положительной оценке нечетных чисел [18].
В развитии качественных значений порядковых числительных прослеживается единая общерусская традиция, однако в ряде случаев проявляется диалектная специфика, связанная с преобладанием сакрального компонента. Таким образом, являющаяся признаком мифологического восприятия мира сакрализация феномена числа, отражающаяся и в его языковой репрезентации, со временем заменяется различными коннотациями качественно-количественного и оценочного характера. Семантизация последовательности счета и ее отдельных элементов ярко проявляется в русском национальном дискурсе.

Сокращенные наименования русских говоров

арх. - архангельские, брян. - брянские, влад. - владимирские, волог. - вологодские, горьк. - горьковские, дон. - донские, иркут. - иркутские, калуж. - калужские, кемер. - кемеровские, новг. - новгородские, новосиб. - новосибирские, олон. - олонецкие, перм. - пермские, пск. - псковские, ряз. - рязанские, свердл. - свердловские, твер. - тверские, тобол. - тобольские, томск. - томские, тюм. - тюменские, урал. - уральские, якут. - якутские, яросл. - ярославские.

\section{ЛИТЕРАТУРА}

1. Вознесенская М. М., Киселева К. Л., Козеренко А. Д. «Тоже мне, бином Ньютона» : операции с числами в составе русских идиом // Логический анализ языка : числовой код в разных языках и культурах / отв. ред. Н. Д. Арутюнова. М. : ЛЕНАНД, 2014. С. 313-327.

2. Словарь русского языка : в 4 т. / под ред. А. П. Евгеньевой. 3-е изд., стер. М. : Рус. яз., 1985-1988.

3. Словарь русских народных говоров. Вып. 1-49. М. ; Л. (СПб.) : Наука, 1965-2016. (СРНГ)

4. Словарь русских старожильческих говоров юга Тюменской области : в 2 т. / под ред. С. М. Беляковой. Тюмень : Изд-во Тюмен. гос. ун-та, 2014.

5. Национальный корпус русского языка. URL: http:// www.ruscorpora.ru (НКРЯ).

6. Сичинава Д. В. Части речи. Материалы для проекта корпусного описания русской грамматики. На правах рукописи. M., 2011. URL: http://rusgram.ru

7. Фатеева Н. А. Первый и второй у Б. Пастернака // Логический анализ языка : числовой код в разных языках и культурах / отв. ред. Н. Д. Арутюнова. М. : ЛЕНАНД, 2014. С. 445-454.

8. Теньер Л. Основы структурного синтаксиса. М. : Прогресс, 1988. 656 с.

9. Титов В. Т. Принципы квантитативной лексикологии (на примере романских языков) : дис. ... д-ра филол. наук. Тверь, 2005. 898 с.

10. Гак В. Г. Теоретическая грамматика французского языка. М. : Добросвет, 2000. 832 с. URL: http:// padaread.com/?book $=39422 \& \mathrm{pg}=2$

11. Иванов B. B. Чёт и нечет : Асимметрия мозга и знаковых систем. М. : Сов. радио, 1978. 184 с. 
12. Мечковская Н. Б. Концепты «начало» и «конец» : тождество, антонимия, асимметричность // Логический анализ языка. Семантика начала и конца / отв. ред. Н. Д. Арутюнова. М. : Индрик, 2002. С. 109-120.

13. Степанов Ю. С. Счет, имена чисел, алфавитные знаки чисел в индоевропейских языках // Вопросы языкознания. 1989. № 4. С. 46-72.

14. Топоров В. Н. Числа // Мифы народов мира : энциклопедия : в 2 т. Т. 2. 2-е изд. М. : Советская энциклопедия, 1994. С. 629-631.

15. Толстая С. М. Число // Славянская мифология : энциклопедический словарь. Изд. 2-е. М. : Междунар. отношения, 2011. С. 488-489.

16. Иноуэ Ю. Что лежит на границе числительных «4» и «5»? // Мир русского слова. 2006. № 4. С. 56-62.

17. Валенцова М. М., Седакова И. А. Первый - последний // Славянские древности : этнолингвистический словарь : в 5 т. Т. 3. М. : Международные отношения, 2004. C. 674-679.

18. Толстая C. М. Чет - нечет // Славянские древности : этнолингвистический словарь : в 5 т. Т. 5. М. : Международные отношения, 2014. С. 537-541.

\section{REFERENCES}

1. Voznesenskaya M. M., Kiseleva K. L., Kozerenko A. D. «Tozhe mne, binom N'yutona» : operatsii s chislami v sostave russkikh idiom ["Too much for me, Newton's Binom": operations with numbers in Russian idioms]. In Logicheskij analiz yazyka: Chislovoj kod v raznykh yazykakh i kul'turakh / Otv. red. N. D. Arutyunova. Moscow: LENAND, 2014. Pp. 313-327.

2. Slovar' russkogo yazyka: v 4 t. [Russian dictionary: in 4 volumes]. Moscow: Rus. jaz., 1985-1988.

3. Slovar' russkikh narodnykh govorov. Vyp. 1-49 [Dictionary of Russian folk dialects, Vol. 1-49]. Moscow, Leningrad (SPb): Nauka, 1965-2016.

4. Slovar' russkikh starozhil'cheskikh govorov yuga Tyumenskoj oblasti / pod red. S. M. Belyakovoj [Dictionary of old Russian dialects of the South of the Tyumen region / ed. by S. M. Belyakova]. Tyumen: Izd-vo Tyumenskogo gos. universiteta, 2014. V 2 t.

5. Natsional'nyj korpus russkogo yazyka. Elektronnyj resurs [National corpus of the Russian language]. Available at: http://www.ruscorpora.ru

6. Sichinava D. V. Chasti rechi. Materialy dlya proekta korpusnogo opisaniya russkoj grammatiki. Na pravakh rukopisi [Parts of speech. Materials for the project of corpus

Тюменский государственный университет

Белякова С. М., профессор кафедры русского языка и общего языкознания

E-mail: smbelyakova@gmail.com

Поступила в редакцию 11 мая 2020 г.

Принята к публикаичи 25 сентября 2020 г. description of Russian grammar. On the rights of the manuscript]. Moscow, 2011. Available at: http://rusgram.ru

7. Fateeva N. A. Pervyj i vtoroj u B. Pasternaka [The First and second in B. Pasternak]. In Logicheskij analiz yazyka: CHislovoj kod v raznykh yazykakh i kul'turakh / Otv. red. N. D. Arutyunova. Moscow: LENAND, 2014. Pp. 445-454.

8. Teniers L. Osnovy strukturnogo sintaksisa [Fundamentals of structural syntax]. Moscow: Progress, $1988.656 \mathrm{p}$.

9. Titov V. T. Printsipy kvantitativnoj leksikologii (na primere romanskikh yazykov). Dissertatsiya na soiskanie uchenoj stepeni doktora filologicheskikh nauk [Principles of quantitative lexicology (on the example of romance languages). Dissertation for the degree of doctor of Philology]. Tver', 2005. 898 p.

10. Gak V. G. Teoreticheskaya grammatika frantsuzskogo yazyka [Theoretical grammar of the French language]. Moscow: Dobrosvet, 2000. 832 p. Available at: http:// padaread.com/?book $=39422 \&$ pg $=2$

11. Ivanov V. V. Chyot i nechet: Asimmetriya mozga i znakovykh sistem [Odd And even: Asymmetry of the brain and sign systems]. Moscow: Sov. radio, 1978. $184 \mathrm{p}$.

12. Mechkovskaya N. B. Kontsepty «nachalo» $\mathrm{i}$ «konets»: tozhdestvo, antonimiya, asimmetrichnost' [Concepts "beginning" and "end": identity, antonymy, asymmetry]. In: Logicheskij analiz yazyka: Semantika nachala $i$ kontsa / Otv. red. N. D. Arutyunova. Moscow: Indrik, 2002. Pp. 109-120.

13. Stepanov Yu. S. Schet, imena chisel, alfavitnye znaki chisel v indoevropejskikh yazykakh [Account, names of numbers, alphabetic signs of numbers in Indo-European languages]. In: Voprosy yazykoznaniya. 1989. No. 4. Pp. 46-72.

14. Toporov V. N. Chisla [Numbers]. In: Mify narodov mira: EHntsiklopediya. V 2-kh t. T. 2. Vtoroe izdanie. Moscow: Sovetskaya ehntsiklopediya, 1994. Pp. 629-631.

15. Tolstaya S. M. Chislo [Number]. In: Slavyanskaya mifologiya. Ehntsiklopedicheskij slovar'. Izd. 2-e. Moscow: Mezhdunar. otnosheniya, 2011. Pp. 488-489.

16. Inoue Yu. Chto lezhit na granitse chislitel'nykh «4» $\mathrm{i} \ll 5 »$ ? [What lies on the border of the numerals "4" and "5"?]. In: Mir russkogo slova. 2006. No. 4. Pp. 56-62.

17. Valentsova M. M., I. A. Sedakova. Pervyj-poslednij [First - last]. In: Slavyanskie drevnosti: Ehtnolingvisticheskij slovar'. V 5-tit. T. 3. Moscow: Mezhdunarodnye otnosheniya, 2004. Pp. 674-679.

18. Tolstaya S. M. Chet - nechet [Even - Odd]. In: Slavyanskie drevnosti: Ehtnolingvisticheskij slovar'. V 5-ti t. T. 5. Moscow: Mezhdunarodnye otnosheniya, 2014. Pp. 537-541.

Tyumen State University

Belyakova S. M., Professor of the Russian Language and General Linguistics Department

E-mail: smbelyakova@gmail.com

Received: 11 May 2020

Accepted: 25 September 2020 


\section{Для цитирования:}

Белякова С. М. О семантическом потенциале порядковых числительных в русском языке // Вестник Воронежского государственного университета. Серия: Лингвистика и межкультурная коммуникация. 2020. № 4. C. 147-155. DOI: https://doi.org/10.17308/lic.2020.4/3090

\section{For citation:}

Belyakova S. M. On the semantic potential of ordinal numerals in the Russian language. Proceedings of Voronezh State University. Series: Linguistics and Intercultural Communication. 2020. No. 4. Pp. 147-155. DOI: https://doi. org/10.17308/lic.2020.4/3090 